\title{
TENSILE DAMAGE CONCRETE: ANALYSIS OF AN EXPERIMENTAL TECHNIQUE
}

\author{
by \\ Dorothée Boudon-Cussac, François Hild and Gilles Pijaudier-Cabot
}

\begin{abstract}
The characterization of the tensile behavior of unreinforced and fiber-reinforced cement and concrete is delicate because of strain localization which introduces a strong heterogeneity of the strain throughout the specimen and complicates the interpretation of test data. An experimental technique to distribute damage is analyzed in the framework of Continuum Damage Mechanics by introducing internal variables to model the degradation mechanisms taking place in this configuration. A mechanism-based formulation is used to derive the state potential and the kinetic laws. Comparisons are performed for cement matrices with different volume fractions and orientations of short fibers. The paper shows the shortcomings of this experimental technique while it is still possible to use it in order to compare the responses of plain and fiber-reinforced concrete.
\end{abstract}




\section{Introduction}

The development of Fiber-Reinforced Cement and Concrete (FRC) is mainly due to the gain in toughness and ductility expected by the presence of short fibers bridging cracks. Short fibers tend to increase the ductility and toughness of the material rather than its ultimate strength. The addition of fibers is of interest because of their potential improvement of the material properties for example in large strain regimes (e.g., seismic excitations) or in impact problems where high fracture toughness is a prominent characteristic. Furthermore, the penetration of water and corrosive agents plays a major role in many deterioration mechanisms of cement and concrete (e.g., freeze thaw damage, sulfate attack, alkali-aggregate reaction). Since the permeability of cement and concrete increases with the formation of cracks, toughening with fibers to control the crack growth is an indirect means of improving the durability.

The identification of constitutive equations of mortar, concrete and FRCs in tension is usually difficult to carry out from a direct uniaxial test, because of strain localization leading to the formation of a single macrocrack (e.g., see (Mazars and Berthaud 1989)). Concrete and FRC are strain softening materials and experimental techniques which avoid strain localization and exhibit the softening response of the material in a stable fashion are difficult, if not impossible, to devise. In most situations, the softening response of the material is obtained indirectly from fracture tests (e.g., see (Guinea et al. 1994)) or size effect tests (Bazant 1986). 
In order to delay or avoid strain localization during a tensile test, one possibility is to avoid localization instability and to prescribe the global and local strains in the tested material so that the softening part of the stress / strain can be monitored. This goal can be achieved with the addition of primary reinforcements, e.g., a significant volume fraction of continuous fibers (denoted by bars later on) acting like reinforcement bars in reinforced concrete. Inspired by the experimental analysis of L'Hermite (1960), a special tension test designed for preventing strain localization to occur as much as possible and obtaining distributed damage in a tension specimen was devised by Bazant and Pijaudier-Cabot (1989) and modified by Mazars et al. $(1989 ; 1990)$ in order to identify the response of concrete in tension with distributed cracking. This experimental procedure will be referred to as "Identification of Distributed Damage" (ID2) in the remaining part of the paper. The specimen consists of twelve $8 \times 8 \times 250 \mathrm{~mm}^{3}$ aluminum bars glued on $38 \times 80 \times 160 \mathrm{~mm}^{3}$ prismatic specimens (Fig. 1) to avoid the formation of a single crack. Three-dimensional Finite Element simulations have been used to analyze the homogeneity of the stresses in the prismatic concrete specimen and it was found that the bars do not modify drastically the state of stress in concrete which is very close to pure tension (Mazars and Berthaud 1989; Sun 1989). The aim of the present paper is to analyze this experimental technique with a broader interpretation of the test data and to implement it for specimens with different volume fractions and orientations of short fibers. 
Because the interface between the aluminum bars and the cementitious specimen is considered to be perfect (i.e., no debonding is assumed to occur), the standard interpretation of the test data is quite straightforward. The underlying behavior of concrete is deduced by assuming that the specimen is a parallel system of concrete and aluminum bars (Mazars and Berthaud 1989; Breysse and Schmitt 1991). The assumption of a perfect interface between concrete and the reinforcement needs to be better supported. The influence of the interface will be explicitly considered and discussed in the present analysis. Furthermore, the effect of short fibers (acting as secondary reinforcement in the experiment) in cementitious prismatic specimens will be analyzed from the experimental point of view with the same technique.

The first part of the paper reviews the main results pertaining to the specimen analyzed as a composite material made of a matrix (concrete, FRC) and fibers (aluminum bars). To make the analysis tractable and simple, a one-dimensional approximation is used to describe the mechanical behavior of the composite. Because the specimen is treated as a composite, the effects of matrix-cracking, interface debonding and sliding appear explicitly. These main ingredients are then introduced in a continuum description from which the interpretation of the test data is more tractable because it remains at the mesoscopic level (that is the level of the specimen) with references to the microstructural state of degradation of the specimen. The analysis of experiments on unreinforced concrete shows that the mechanical response of the 
interface is quite important in this experimental technique and that it cannot be considered to be perfectly bonded. Finally, the effect of short fibers on the response of the tension specimen is discussed.

\section{Composite Model}

Loading a composite consisting of a brittle matrix (concrete or FRC) supported by stronger fibers (aluminum bars), usually causes multiple matrix-cracking (Aveston et al. 1971) accompanied by debonding and sliding at the fiber/matrix interface if the interface is sufficiently weak. Because of stress redistribution between the fiber and matrix, the matrix-cracking density usually saturates, i.e., the crack spacing reaches a lower bound because the shear transfer capability of the interface across each matrix crack is reached and because the stress cannot be redistributed enough from the fibers on to the matrix in order to reach the tensile strength of the matrix.

Matrix-cracking is responsible for the decrease of stiffness observed in experiments on brittle-matrix composites, debonding and sliding at the fiber-matrix interface are the source of irreversible strains. The cell model first proposed by Aveston and Kelly (1973) will be used with the introduction of a debond energy at the front of the slipping region (Hutchinson and Jensen 1990). In the present model, the composite is a series of unit cells of length equal to the average crack-spacing. 


\section{Cell Model Description}

In the unit cell shown in Fig. 2, the elastic moduli of the fiber and matrix are $\mathrm{E}_{\mathrm{f}}$ and $\mathrm{E}_{\mathrm{m}}$ respectively, the volume fraction of the fiber is $f$ and $H_{f}$ is the fiber equivalent height (so that $f=H_{f} / H$, see Fig. 2). The elastic modulus of the undamaged composite is $\mathrm{E}=\mathrm{fE}_{\mathrm{f}}+(1-$ f) $\mathrm{E}_{\mathrm{m}}$. Matrix-cracking (transverse cracks) occurs when the applied stress reaches a material value $\sigma_{\mathrm{mc}}$ (Aveston et al. 1971; Budiansky et al. 1986) and the average distance between cracks is denoted by $2 \mathrm{~L}$. The debond length at the fiber/matrix interface is $2 l_{\mathrm{d}}$, and the interface is assumed to have a constant shear strength $\tau$ and a critical energy release rate $G_{\mathrm{d}}$ to extend the interface crack. Following Outwater and Murphy (1969), this critical energy release rate $G_{\mathrm{d}}$ can be represented as a debond strength $\sigma_{\mathrm{d}}$ which introduces simplicity in later calculations. This debond strength can be expressed in terms of $G_{\mathrm{d}}$ as

$$
\sigma_{d}=\sqrt{\frac{2(1-f) E_{m} E_{f} G_{d}}{H_{f} E}}
$$

To define the state in the unit cell, the values for the crack spacing $2 \mathrm{~L}$, the debond length $2 l_{\mathrm{d}}$, and the interface properties $\sigma_{\mathrm{d}}$ and $\tau$ must be known. The latter are unknown material parameters but are assumed to be constant. 


\section{Mechanical Response}

The initial response of the composite is elastic when the modulus is $\mathrm{E}$. When the matrix-cracking stress $\sigma_{\mathrm{mc}}$ is reached, matrixcracking occurs which is accompanied by matrix-fiber interface debonding and slip inducing stiffness losses and inelastic strains. The presence of cracks induces additional stresses in the matrix $\rho_{m}(x)$ and in the fiber $\rho_{f}(x)$ that are self-balanced

$$
(1-f) \rho_{m}(x)+f \rho_{f}(x)=0
$$

where $0 \leq \mathrm{x} \leq \mathrm{L}$ is the microscopic coordinate (see Fig. 2), so that the local strains in the fiber and in the matrix are expressed as

$$
\varepsilon_{\mathrm{f}}(\mathrm{x})=\frac{\sigma}{\mathrm{E}}+\frac{\rho_{\mathrm{f}}(\mathrm{x})}{\mathrm{E}_{\mathrm{f}}} ; \varepsilon_{\mathrm{m}}(\mathrm{x})=\frac{\sigma}{\mathrm{E}}+\frac{\rho_{\mathrm{m}}(\mathrm{x})}{\mathrm{E}_{\mathrm{m}}}
$$

Their combined effect yields a non linear strain $(\varepsilon) /$ stress $(\sigma)$ relationship

$$
\varepsilon=\frac{1}{L} \int_{0}^{L} \varepsilon_{f}(x) d x=\frac{\sigma}{E}+\varepsilon^{a}
$$

where $\varepsilon^{\mathrm{a}}$ is the additional strain induced by all the degradation mechanisms 


$$
\varepsilon^{\mathrm{a}}=\frac{1}{\mathrm{~L}} \int_{0}^{\mathrm{L}} \frac{\rho_{\mathrm{f}}(\mathrm{x})}{\mathrm{E}_{\mathrm{f}}} \mathrm{dx} .
$$

The degradation mechanisms lead to an overall crack opening displacement $\Delta$ which is expressed as

$$
\Delta=\int_{0}^{L}\left[\frac{\rho_{\mathrm{f}}(\mathrm{x})}{\mathrm{E}_{\mathrm{f}}}-\frac{\rho_{\mathrm{m}}(\mathrm{x})}{\mathrm{E}_{\mathrm{m}}}\right] \mathrm{dx}
$$

By using Eqns. (2), (5) and (6), the crack opening displacement $\Delta$ can be related to the additional strain $\varepsilon^{\mathrm{a}}$ by

$$
\varepsilon^{a}=\frac{(1-f) E_{m} \Delta}{E L}
$$

The crack opening displacement is made up of the sum two terms, viz. a first one related to the applied stress and corresponding to an elastic contribution $\left(\Delta^{\mathrm{e}}\right)$, and a second one relative to friction and referred to as inelastic contribution $\left(\Delta^{\mathrm{i}}\right)$

$$
\Delta=\Delta^{\mathrm{e}}+\Delta^{\mathrm{i}}
$$

In fiber-reinforced composites, the two contributions need to be accounted for. Matrix-cracking is described by an elastic contribution of the crack opening displacement and debonding and 
sliding are related to the second contribution. In the following, the two mechanisms will be analyzed separately.

To model matrix-cracking, one of the simplest models will be used, i.e., the Cox model (1952). The additional stress field in the fiber $\rho_{\mathrm{f}}^{\mathrm{e}}(\mathrm{x})$ is a well-known solution to a second order differential equation

$$
\rho_{\mathrm{f}}^{\mathrm{e}}(\mathrm{x})=\frac{\sigma}{\mathrm{E}} \frac{\cosh \left[\frac{\beta(\mathrm{x}-\mathrm{L})}{\mathrm{H}_{\mathrm{m}}}\right]}{\mathrm{A} \cosh \left[\frac{\beta \mathrm{L}}{\mathrm{H}_{\mathrm{m}}}\right]}
$$

in which the dimensionless quantities are defined by

$$
A=\frac{f E_{f}}{(1-f) E_{m}} \quad ; \quad \beta^{2}=\frac{3 G_{m} E}{f E_{m} E_{f}}
$$

where $G_{m}$ is the shear modulus of the matrix, $2 \mathrm{H}_{\mathrm{m}}$ the crack length (see Fig. 2). The value of the parameter $\beta$ is obtained by assuming that the displacement field in the matrix is parabolic through the thickness (y-direction). Another kinematic hypothesis would alter the number 3 but not the other material constants in $\beta$. By using Eqns. (5) and (9), the additional strain $\varepsilon^{\mathrm{a}-\mathrm{e}}$ relative to $\Delta^{\mathrm{e}}$ is expressed as

$$
\varepsilon^{\mathrm{a}-\mathrm{e}}=\frac{\sigma}{\mathrm{E}} \Omega ; \omega=\frac{\mathrm{H}_{\mathrm{m}}}{\beta \mathrm{L}} ; \Omega=\frac{\omega}{\mathrm{A}} \tanh \left(\frac{1}{\omega}\right)
$$


This additional strain causes an increase of the Gibbs' specific energy of the composite $\Delta \varphi$

$$
\Delta \varphi=\frac{\sigma^{2}}{2 \mathrm{E}} \Omega
$$

When interface slip occurs, it is accompanied by an additional crack opening displacement $\Delta^{\mathrm{i}}$. This displacement $\Delta^{\mathrm{i}}$ gives rise to a self-balancing stress field along the friction (or slip) length $2 l_{\mathrm{f}}\left(\leq 2 l_{\mathrm{d}}\right)$ in the matrix, $\rho_{\mathrm{m}}^{\mathrm{i}}(\mathrm{x})$ and in the fiber, $\rho_{\mathrm{f}}^{\mathrm{i}}(\mathrm{x})$. The self-balancing stress fields cause inelastic strains given by (see Eqns. (6) and (7))

$$
\varepsilon^{\mathrm{i}}=\frac{1}{\mathrm{~L}} \int_{0}^{\mathrm{L}} \frac{\rho_{\mathrm{f}}^{\mathrm{i}}(\mathrm{x})}{\mathrm{E}_{\mathrm{f}}(\mathrm{x})} \mathrm{dx}=\frac{(1-\mathrm{f}) \mathrm{E}_{\mathrm{m}}}{\mathrm{E}} \frac{\Delta^{\mathrm{i}}}{\mathrm{L}} .
$$

By assuming a constant interfacial strength $\tau$ and considering the debond strength defined in Eqn. (1), the residual stress in the fiber $\rho_{\mathrm{f}}^{\mathrm{i}}(\mathrm{x})$ is expressed as

$$
\rho_{\mathrm{f}}^{i_{f}}(\mathrm{x})=\left\{\begin{array}{lr}
\sigma_{\mathrm{d}}+\frac{\tau}{\mathrm{H}_{\mathrm{f}}}\left(l_{\mathrm{d}}-\mathrm{x}\right) & \text { if } \mathrm{x} \leq l_{\mathrm{d}} \\
0 & \text { otherwise }
\end{array}\right.
$$

so that the expression for the irreversible $\varepsilon^{i}$ (see Eqn. (13)) following interfacial slip is given by 


$$
\varepsilon^{\mathrm{i}}=\lambda_{\mathrm{d}} \mathrm{T}_{\mathrm{d}}\left(1+\Sigma_{\mathrm{d}}\right)
$$

where the primary dimensionless group $\mathrm{T}_{\mathrm{d}}$ is defined by

$$
\mathrm{T}_{\mathrm{d}}=\frac{\tau l_{\mathrm{d}}}{2 \mathrm{E}_{\mathrm{f}} \mathrm{H}_{\mathrm{f}}}
$$

and is a measure of the average strain due to friction over the debond length $l_{\mathrm{d}}$. The evolution of $\mathrm{T}_{\mathrm{d}}$ during initial loading is given by

$$
\mathrm{T}_{\mathrm{d}}=\frac{1}{2 \mathrm{~A}}\left(\frac{\sigma}{\mathrm{E}}-\mathrm{A} \frac{\sigma_{\mathrm{d}}}{\mathrm{E}_{\mathrm{f}}}\right)
$$

since $\sigma_{\mathrm{f}}(\mathrm{x}=0)=\sigma / \mathrm{f}$. The dimensionless parameters $\lambda_{\mathrm{d}}$ and $\Sigma_{\mathrm{d}}$ are given by

$$
\lambda_{\mathrm{d}}=\frac{l_{\mathrm{d}}}{\mathrm{L}}=\mathrm{B} \omega \mathrm{T}_{\mathrm{d}} ; \quad \Sigma_{\mathrm{d}}=\frac{2 \sigma_{\mathrm{d}} \mathrm{H}_{\mathrm{f}}}{\tau l_{\mathrm{d}}}=\frac{\sigma_{\mathrm{d}}}{\mathrm{E}_{\mathrm{f}}} \frac{1}{\mathrm{~T}}
$$

where $\mathrm{B}$ is a dimensionless parameter defined by

$$
B=\frac{2 \beta \mathrm{fE}_{\mathrm{f}}}{(1-\mathrm{f}) \tau} \text {. }
$$

Since $\lambda_{d}$ and $\Sigma_{d}$ are expressed in terms of $\omega, T_{d}$ and material constants, $\omega$ and $\mathrm{T}_{\mathrm{d}}$ are referred to as primary dimensionless groups and $\lambda_{d}$ and $\Sigma_{d}$ as secondary dimensionless groups. The parameter 
$\lambda_{d}$ varies between 0 and 1 . When $\lambda_{d}=1$, matrix-cracking saturates. When the ratio $\Sigma_{\mathrm{d}}$ is large, the material is said to behave in a high debond energy (HDE) regime and when the ratio is small, the regime is described as low debond energy (LDE): see (Evans et al., 1994).

Debonding and friction also cause elastic energy to be stored in the material. The elastic energy densities in the matrix $\left(\psi_{m}\right)$ and in the fiber $\left(\psi_{\mathrm{f}}\right)$ are needed to compute the non-recoverable energy density $\psi^{\mathrm{i}}$ of the composite

$$
\psi_{\mathrm{f}}(\mathrm{x})=\frac{\left[\rho_{\mathrm{f}}^{\mathrm{i}}(\mathrm{x})\right]^{2}}{2 \mathrm{E}_{\mathrm{f}}} \quad ; \quad \psi_{\mathrm{m}}(\mathrm{x})=\frac{\left[\rho_{\mathrm{m}}^{\mathrm{i}}(\mathrm{x})\right]^{2}}{2 \mathrm{E}_{\mathrm{m}}}
$$

so that the non-recoverable energy $\psi^{\mathrm{i}}$ following sliding is given by

$$
\psi^{i}=\frac{1}{\bar{L}} \int_{0}^{L}\left[f \psi_{f}(x)+(1-f) \psi_{m}(x)\right] d x
$$

By noting that the stresses $\rho_{\mathrm{f}}^{\mathrm{i}}(\mathrm{x})$ and $\rho_{\mathrm{m}}^{\mathrm{i}}(\mathrm{x})$ are self-balanced, the expression for the non-recoverable energy for the composite is found to be

$$
\psi^{i}=\frac{E A}{2 L} \int_{0}^{L}\left[\frac{\rho_{f}^{i}(x)}{E_{f}(x)}\right]^{2} d x
$$


By using Eqn. (14), the expression for the non-recoverable energy $\psi^{\mathrm{i}}$ following interfacial slip is

$$
\psi^{\mathrm{i}}=\frac{\mathrm{E}}{2} \mathrm{~A} \lambda_{\mathrm{d}} \mathrm{T}_{\mathrm{d}}^{2}\left[\frac{1}{3}+\left(1+\Sigma_{\mathrm{d}}\right)^{2}\right]
$$

In the next section, the results of the present derivations are reformulated within the framework of Continuum Mechanics.

\section{Continuum Representation}

The model presented in the preceding section helps to define the state variables and to calculate the free energy density (also called state potential) from which the corresponding forces can be deduced. Here, we are going to re-write the model by using the technique of Continuum Mechanics and the concept of state variables (Rice 1971; Germain et al. 1983). It is recalled that only a one-dimensional analysis is carried out herein.

\section{State Potential}

The free energy density for a given state is calculated by performing two elastic calculations following approaches introduced by Volterra (1907), and used to analyze the elastic behavior of homogeneous and isotropic media (Volterra 1907; Love 1927) and the influence of inclusions in an infinite medium (Eshelby 1957). The first step consists of calculating the elastic energy of a cracked 
system when the fiber ( $f$ ) is slided with respect to the matrix $(m)$ by an amount $\Delta^{\mathrm{i}}$ over a length $2 l_{\mathrm{f}}=2 l_{\mathrm{d}}$ with no applied external load. The second step involves an elastic loading of a cracked system where friction is prevented.

The first step corresponds to the effect of debonding at the fibermatrix interface. The derivation of this non-recoverable energy has been determined in the previous section (see Eqns. (22) and (23)) and is rewritten as follows

$$
\psi^{\mathrm{i}}=\frac{\mathrm{E}}{2} \frac{\left(\varepsilon^{\mathrm{i}}\right)^{2}}{\mathrm{~d}} .
$$

Equation (24) can be found in (Andrieux 1981; Andrieux et al. 1986) to model concrete and rocks for which only one degradation mechanism was considered. The general expression of the damage variable d is derived from Eqns. (13), (22) and (24)

$$
d=\frac{1}{A}\left[\frac{1}{L} \int_{0}^{L}\left\{\frac{\rho_{f}^{i}(x)}{E_{f}(x)}\right\} d x\right]^{2} \frac{1}{L} \int_{0}^{L}\left[\frac{\rho_{f}^{i}(x)}{E_{f}(x)}\right]^{2} d x
$$

From the micromechanical model with a constant shear strength $\tau$ defined in the previous section, the damage variable $d$ is expressed as

$$
\mathrm{d}=\frac{\lambda_{\mathrm{d}}}{\mathrm{A}}\left[1+\frac{1}{3}\left(1+\Sigma_{\mathrm{d}}\right)^{-2}\right]^{-1}
$$


and is a measure of the relative debond length $\lambda_{\mathrm{d}}=l_{\mathrm{d}} / \mathrm{L}$. The value of the square bracket varies between 1 and $4 / 3$ for a high and low debond energy material respectively, which means that the value of the dimensionless group $\Sigma_{\mathrm{d}}$ has a small effect on $\mathrm{d}$.

In the second step, the recoverable free energy density describes the effects of matrix-cracking. In the Continuum Mechanics framework, the presence of a crack results in a stiffness reduction defined by an internal damage variable D (Lemaitre and Dufailly 1977; Chaboche 1982) so that the current Young's modulus $\tilde{\mathrm{E}}=\mathrm{E}(1-$ D). The recoverable part $\psi^{\mathrm{e}}$ of the Helmholtz free energy density becomes

$$
\psi^{\mathrm{e}}=\frac{E(1-D)\left(\varepsilon^{\mathrm{e}}\right)^{2}}{2}
$$

where $D$ is deduced from the micromechanical analysis (see Eqn. (12))

$$
\mathrm{D}=\frac{\Omega}{1+\Omega}
$$

and $\Omega$ is a measure of the crack density defined in Eqns. (11) and $\varepsilon^{\mathrm{e}}$ the elastic strain.

The total free energy density is the sum of the two components of energy in which $\varepsilon^{e}=\varepsilon-\varepsilon^{i}$. The total free energy density is expressed with four state variables which are the total strain $\varepsilon$, and three internal variables, viz. a damage variable $\mathrm{D}$ modeling the loss of 
stiffness due to cracking, an inelastic strain $\varepsilon^{\mathrm{i}}$ due to debonding and sliding and a damage variable $d$ measuring the amount of nonrecoverable energy due to debonding and slip

$$
\psi=\frac{1}{2} E(1-D)\left(\varepsilon-\varepsilon^{i}\right)^{2}+\frac{E}{2} \frac{\left(\varepsilon^{i}\right)^{2}}{d} .
$$

The forces associated with the state variables are

$$
\begin{gathered}
\sigma=\frac{\partial \psi}{\partial \varepsilon}=E(1-D)\left(\varepsilon-\varepsilon^{i}\right) ; Y=-\frac{\partial \psi}{\partial D}=\frac{E}{2}\left(\frac{\sigma}{1-D}\right)^{2} \\
X=-\frac{\partial \psi}{\partial \varepsilon^{i}}=\sigma-E \frac{\varepsilon^{i}}{d} ; y=-\frac{\partial \psi}{\partial d}=\frac{E}{2}\left(\frac{\varepsilon^{i}}{d}\right)^{2}
\end{gathered}
$$

Equation (30.1) defines the macroscopic stress $\sigma$ and Eqn. (30.2) the energy release rate density $\mathrm{Y}$ associated with matrix-cracking. Equation (30.2), shows that the energy release rate density $\mathrm{Y}$ is proportional to the square of the effective stress $\sigma /(1-D)$. Similarly, Eqn. (30.3) defines the back stress $\mathrm{X}$ associated with sliding whose exact value depends upon the interfacial properties. Lastly, Eqn. (30.4) defines the energy release rate density y associated to the residual stresses due to debonding and sliding.

The matrix-cracking damage variable $\mathrm{D}$ is directly related to the average crack spacing $2 \mathrm{~L}$, and the inelastic portion of the crack opening displacement $\Delta^{i}$ to the inelastic strain $\varepsilon^{i}$. In the next subsection, it will be shown that when the variables $D$ and $\varepsilon^{i}$ are known, the damage variable $\mathrm{d}$ can be calculated from micromechanics. 


\section{Evolution Laws}

The final step in establishing the model is to determine the evolution laws $F_{D}, F_{d}, F_{i}$ which relate the state variables $\left(D, d, \varepsilon^{i}\right)$ to their associated forces $(\mathrm{Y}, \mathrm{y}, \mathrm{X})$

$$
\mathrm{D}=\mathrm{F}_{\mathrm{D}}(\mathrm{Y}) ; \varepsilon^{\mathrm{i}}=\mathrm{F}_{\mathrm{i}}(\mathrm{X}) ; \mathrm{d}=\mathrm{F}_{\mathrm{d}}(\mathrm{y})
$$

Under isothermal conditions, the model is thermodynamically admissible when the intrinsic dissipation $\mathcal{D}$ is positive

$$
\mathcal{D}=\mathrm{Y} \dot{\mathrm{D}}+\mathrm{X} \dot{\varepsilon} \boldsymbol{i}+\mathrm{y} \dot{\mathrm{d}} \geq 0
$$

where ' $\bullet$ ' denotes the time derivative.

We assume that the growth of matrix cracking represented by the variable $D$ is a function of its associated force $Y$ (see Eqn. (31.1)). The initial cracking condition can be written as

$$
\mathrm{Y}=\mathrm{Y}_{\mathrm{c}}
$$

From Eqns. (30.2) and (33), the matrix cracking stress $\sigma_{\mathrm{mc}}$ is found to be

$$
\sigma_{\mathrm{mc}}=\sqrt{2 \mathrm{Y}_{\mathrm{c}} \mathrm{E}}
$$


The micromechanics associated with crack spacing is complex and involves statistical calculations (Curtin 1993). Instead we use the experimental observation of Domergue (1995) that the crack density $\omega(\approx \mathrm{A} \Omega)$ satisfies a linear relationship with the applied stress $\sigma$

$$
\omega=\frac{\sigma-\sigma_{\mathrm{mc}}}{\sigma_{0}} ; \sigma_{0}=\frac{\left(\sigma_{\mathrm{s}}-\sigma_{\mathrm{mc}}\right) \beta \mathrm{L}_{\mathrm{s}}}{\mathrm{H}_{\mathrm{m}}}
$$

where the normalizing constants $\mathrm{L}_{\mathrm{s}}$ and $\sigma_{\mathrm{s}}$ correspond to the values of $L$ and $\sigma$ at saturation. Eliminating the crack density $\omega$ from the last two equations and using the expression (30.2) for Y in Eqn. (35.1) combined to Eqn. (33), the evolution law for $\mathrm{D}$ in terms of $\mathrm{Y}$ becomes

$$
\mathrm{D}=\frac{2 \sqrt{\mathrm{Y}}+\sqrt{\mathrm{Y}_{0}}-\sqrt{\mathrm{Y}_{\mathrm{c}}}-\sqrt{\left(2 \sqrt{\mathrm{Y}}+\sqrt{\mathrm{Y}_{0}}-\sqrt{\mathrm{Y}_{\mathrm{c}}}\right)^{2}-4 \sqrt{\mathrm{Y}}\left(\sqrt{\mathrm{Y}}-\sqrt{\mathrm{Y}_{\mathrm{c}}}\right)}}{2 \sqrt{\mathrm{Y}}}
$$

where

$$
\sqrt{2 \mathrm{EY}_{0}}=\mathrm{A} \sigma_{0} .
$$

The onset of interfacial debonding (when $l_{\mathrm{d}}=0$ ) is characterized by an interfacial debond stress $\sigma_{\mathrm{id}}$ so that

$$
\frac{\sigma_{i d}}{E}=\frac{A \sigma_{d}}{E_{f}}
$$


The growth of the inelastic strain $\varepsilon^{i}$ has been defined by Eqn. (31.2) with the definition of the back stress $X$ given in Eqn. (30.3). Eliminating the slip length $l_{\mathrm{d}}$ between Eqns. (15) and (17), and the crack spacing L (Eqns. (11.2), (11.3) and (35)) gives the relationship between $\varepsilon^{i}$ and the applied stress $\sigma$

$$
\varepsilon^{\mathrm{i}}=\frac{\mathrm{B}}{4 \mathrm{~A}^{2}} \frac{\sigma-\sigma_{\mathrm{mc}}}{\sigma_{0}}\left[\left(\frac{\sigma}{\mathrm{E}}\right)^{2}-\left(\frac{\sigma_{\mathrm{id}}}{\mathrm{E}}\right)^{2}\right] .
$$

The back stress $\mathrm{X}$ is computed by using Eqns. (26) and (30.3)

$$
\mathrm{X}=\sigma-\frac{\sigma+\sigma_{\mathrm{id}}}{2}\left[1+\frac{1}{3}\left(1+2 \frac{\sigma_{\mathrm{id}}}{\mathrm{E}}\left(\frac{\sigma-\sigma_{\mathrm{id}}}{\mathrm{E}}\right)^{-1}\right)^{-2}\right]
$$

The relationship $\varepsilon^{\mathrm{i}}=\mathrm{F}_{\mathrm{i}}(\mathrm{X})$ could have been introduced in an arbitrary form and identified experimentally. Here we take advantage of the analysis of the composite model and incorporate its results directly in the continuum description.

Similarly, the evolution of the interfacial damage $d$ and its associated force $\mathrm{y}$ are written in a parametric form as a function of the applied stress $\sigma$ by using Eqns. (26), (30.4) and (39.1)

$$
\begin{gathered}
\mathrm{d}=\frac{\mathrm{B}}{2 \mathrm{~A}^{2}} \frac{\sigma-\sigma_{\mathrm{id}}}{\mathrm{E}} \frac{\sigma-\sigma_{\mathrm{mc}}}{\sigma_{0}}\left[1+\frac{1}{3}\left(1+2 \frac{\sigma_{\mathrm{id}}}{\mathrm{E}}\left(\frac{\sigma-\sigma_{\mathrm{id}}}{\mathrm{E}}\right)^{-1}\right)^{-2}\right]^{-1} \\
\mathrm{y}=\frac{\mathrm{E}}{8}\left(\frac{\sigma+\sigma_{\mathrm{id}}}{\mathrm{E}}\right)^{2}\left[1+\frac{1}{3}\left(1+2 \frac{\sigma_{\mathrm{id}}}{\mathrm{E}}\left(\frac{\sigma-\sigma_{\mathrm{id}}}{\mathrm{E}}\right)^{-1}\right)^{-2}\right]^{2}
\end{gathered}
$$


It is worth noting that the Clausius-Duhem inequality (32) is

satisfied in the present case since $\mathrm{Y}, \mathrm{X}, \mathrm{y} \geq 0$ and $\dot{\mathrm{D}}, \stackrel{\circ}{\varepsilon}^{\mathrm{i}}, \stackrel{\mathrm{d}}{\mathrm{d}} \geq 0$ under monotonic loading conditions. The present analysis shows that all evolution laws are eventually driven by the applied stress $\sigma$. By contrast, for ductile materials, the driving force is the plastic strain or the cumulative plastic strain, even when damage is observed (Lemaitre 1992).

\section{D Generalization}

The previous results can be generalized to 3D situations (Boudon-Cussac 1996), even though it is believed that the previous 1D approximation keeps the essential features and makes the analysis of the experiments simpler and straightforward. The same set of state variables can be used. However the mathematical nature of each of them is different. The damage variable $\mathrm{D}$ modeling matrix-cracking is anisotropic and can be described by a second order tensor (Burr et al. 1995). A second order tensor is also needed to model the inelastic strains $\varepsilon^{i}$ due to debonding and slip. Lastly, since each operative slip system can be integrated separately in terms of energetic contributions, the damage variables d can be defined separately for each inelastic strain term. Therefore there are as many debond damage terms as non-vanishing inelastic strain components (Burr et al. 1995). Such a constitutive law has been used to model the 
mechanical behavior of ceramic-matrix composites (Burr et al. 1997).

\section{Identification Procedure}

Unload / reload sequences in tension are performed. A typical result is shown in Fig. 3 for an unreinforced cement in an ID2 experiment. At the end of the test, the tangent modulus of the composite approaches that of the volume fraction of aluminum bars (denoted by $\mathrm{fE}_{\mathrm{f}}$ in the figure). It is therefore expected that saturation occurs. This feature will be discussed later on.

The identification procedure is based upon the experimental measurements associated with loading/partial unloadings (Fig. 4) from which the current value of the elastic modulus $\mathrm{E}(1-\mathrm{D})$ and the inelastic strain $\varepsilon^{i}$ can be measured. From these two data, the unknown parameters to be identified, viz. $Y_{c}$ and $Y_{0}$ for the damage evolution law, $\mathrm{B} / 4 \mathrm{~A}^{2}$ and $\sigma_{\mathrm{id}} / \mathrm{E}$ for the inelastic strain change can be determined. These parameters allow to compute the change of the damage variable d with the applied stress $\sigma$ (see Eqn. (40.1)): it is an output of the model.

\section{Experiments on Plain Concrete}

In this section, experimental data obtained for two ID2 specimens made of unreinforced concrete $\left(f_{\mathrm{s}}=0 . \%\right)$ are analyzed. The damage variable $D$, the inelastic strain $\varepsilon^{i}$ as well as the permanent strain $\varepsilon^{p}$ 
(i.e., the strain level when the applied stress vanishes) are recorded as a function of the applied stress $\sigma$.

The experimental relationship observed between $\mathrm{D}$ and $\mathrm{Y}$ is given in Fig. 5. From this curve the values of the following dimensionless parameters can be obtained

$$
\sqrt{\frac{2 \mathrm{Y}_{0}}{\mathrm{E}}}=4.4 \times 10^{-4} \pm 6 \times 10^{-5} \quad ; \quad \sqrt{\frac{2 \mathrm{Y}_{\mathrm{c}}}{\mathrm{E}}}=1.3 \times 10^{-3} \pm 10^{-5}(41.1 ; 2)
$$

from which the matrix-cracking stress $\sigma_{\mathrm{mc}}$ can be derived immediately and has the value $5.1 \pm 0.4 \mathrm{MPa}$, which is in good agreement with the experimental observations of Fig. 3.

The dimensionless parameter $\mathrm{B} / 4 \mathrm{~A}^{2}$ and $\sigma_{\mathrm{id}} / \mathrm{E}$ are identified by using the inelastic strain. By fitting the experimental results of Fig. 6, the values of the dimensionless parameter are

$$
\frac{\mathrm{B}}{4 \mathrm{~A}^{2}}=12 \times 10^{3} \pm 10^{3} ; \frac{\sigma_{\mathrm{id}}}{\mathrm{E}} \approx 0 .
$$

This last result (i.e., $\sigma_{\text {id }}$ vanishes) indicates that the specimen behaves in a low debond energy (LDE) regime. Therefore, the usual assumptions made to identify the underlying behavior of concrete (i.e. perfect bond between aluminum fibers and concrete, $\beta, G_{d} \rightarrow \infty$ ) cannot be used in the present case. When the material behaves in an LDE regime, Eqns. (39) and (40) can be simplified 


$$
\begin{gathered}
\varepsilon^{i}=\frac{B}{4 A^{2}} \frac{\sigma-\sigma_{m c}}{\sigma_{0}}\left(\frac{\sigma}{E}\right)^{2} ; X=\frac{\sigma}{3} \\
d=\frac{3 \mathrm{~B}}{8 \mathrm{~A}^{2}} \frac{\sigma-\sigma_{m c}}{\sigma_{0}}\left(\frac{\sigma}{E}\right) ; y=\frac{2 E}{9}\left(\frac{\sigma}{E}\right)^{2}
\end{gathered}
$$

Equations (43.2) and (43.4) show that there is a linear relationship between $\mathrm{X}$ and $\sigma$, and a parabolic relationship between $\mathrm{y}$ and $\sigma$.

The analysis of the evolution of the inelastic strain shows that there is a change in the evolution pattern for a stress greater than $12 \mathrm{MPa}$, indicating the onset of cracking saturation. This phenomenon is confirmed when the damage variable $d$ is plotted as a function of the applied stress $\sigma$. Figure 7 compares the predictions for HDE and LDE materials with those obtained for the ID2 specimen. As expected an LDE regime is observed (since $\sigma_{\mathrm{id}}$ vanishes).

When the specimen behaves in an LDE regime and the residual stresses are negligible, there exists a very simple relationship (McMeeking and Evans 1990; Hild et al. 1996) between the inelastic strain $\varepsilon^{i}$ and the corresponding permanent strain $\varepsilon^{p}$

$$
\varepsilon^{\mathrm{i}}=2 \varepsilon^{\mathrm{p}}
$$

Figure 8 shows that the predictions of the change of the permanent strain with the applied stress is in reasonable agreement with the experiments. Figures 6,7 and 8 consistently show that the saturation stress is equal to $12 \pm 0.5 \mathrm{MPa}$. On the other hand, Fig. 5 shows that the prediction, a priori only valid up to saturation, can be 
further extended. Beyond the saturation level, the behavior of the ID2 specimen is mainly driven by the aluminum bars and the interface between the bars and the concrete parallelepiped (Fig. 2). It is worth remembering that the interface is weak (indicated by the $\mathrm{LDE}$ regime). The underlying behavior of concrete is very difficult to deduce since the stress state in concrete is not uniform along the loading direction, even in the central part of the specimen. Therefore, the original method for the derivation of the response of concrete seems not to be appropriate and should yield large errors if the influence of the interface is not taken into account.

\section{Experiments on Fiber-Reinforced Concrete}

Although it is difficult to obtain experimentally the behavior of concrete with this testing procedure, it can still serve for comparison purposes. The effect of the addition of short anchored steel fibers (54 $\mathrm{mm}$ in length, $0.85 \mathrm{~mm}$ in diameter, Young's modulus $=210 \mathrm{GPa}$, yield stress $=1200 \mathrm{MPa}$ ) is discussed in this section by comparing the response of specimens with and without short fibers. The comparison at a purely macroscopic level consists of plotting the stress/strain responses for different volume fractions of short fibers $\left(f_{s}=0 ., 0.1,0.3\right.$ and $\left.0.6 \%\right)$. For the volume fraction $f_{s}=0.3$, three orientations are considered : $0, \pm 15$ and $\pm 30^{\circ}$ with respect to the loading direction. The other volume fractions are concerned with the $0^{\circ}$-orientation only. 
Figure 9 shows that the volume fraction $f_{s}=0 . \%$ constitutes a lower bound to the stress / strain behavior. However the exact value of the volume fraction and the fiber orientation is not very important. It can be noticed that when the fibers do not lie along the loading direction, the stress/strain response is very close to that of unreinforced cement.

The experimental relationship between the damage variable $\mathrm{D}$ and its associated force $\mathrm{Y}$ is shown in Fig. 10. The effect of the addition of short fibers becomes more significant. When the fiber orientation coincides with the loading direction, the most important feature is the presence of short fibers but not their relative volume fraction. This result indicates that the cracks are probably bridged but by very few short fibers so that the actual value of the volume fraction is unimportant. On the other hand, when the fiber orientation is equal to $\pm 15^{\circ}$ and $\pm 30^{\circ}$ with respect to the loading direction, the observed damage values lie in the scatter of the damage law for unreinforced cement.

Figure 11 shows the same effect of fiber volume fraction and orientation. When the fiber orientation is equal to $0^{\circ}$, the overall inelastic strain is more influenced by the presence of short fibers rather than their respective volume fraction. When the fiber orientation is equal to $\pm 15^{\circ}$ and $\pm 30^{\circ}$, the corresponding inelastic strain is very close to that in unreinforced concrete. The effect of crack bridging is negligible in that case. 


\section{Conclusions}

1- A Continuum Damage Mechanics formulation has been applied to plain and fiber-reinforced cement specimens reinforced by aluminum bars. In addition to the total strain, the internal variables which define the state of the material have been identified. Concretecracking is described by one damage variable, debonding and sliding are modeled by an inelastic strain and another damage variable measuring the amount of non-recoverable energy. These variables are related to microscopic quantities introduced to analyze the underlying degradation mechanisms.

2- Cementitious specimens reinforced by aluminum bars used herein exhibit a low debond energy regime (i.e. the interface does not remain perfectly bonded). The classical identification procedure cannot be used to infer the behavior of concrete from the response of the composite specimen. However, this experimental technique can produce useful comparison between unreinforced and various types of reinforced specimens.

3- When the short fibers are aligned along the loading direction, this type of experiment is more sensitive to the presence or the lack of short fibers in concrete than the actual volume fraction (up to $0.6 \%$ ). However, in some other cases, the effect of fiber volume fraction can be more significant (e.g., three point flexure tests (Bentur and Mindess 1990; Boudon-Cussac 1996)). When the fiber orientation and the loading direction do not coincide, the effect of the fibers on the mechanical response is negligible when compared to 
unreinforced cement. This fact indicates that the bridging effect becomes negligible in comparison with that induced by the aluminum bars (when the fiber volume fraction is equal to $0.3 \%$ ). 


\section{Appendix. References}

Andrieux, S. (1981). "Un modèle de matériau microfissuré avec frottement." C. R. Acad. Sci. Paris, Série II (t. 293), 329-332 (in French).

Andrieux, S., Bamberger, Y., and Marigo, J.-J. (1986). "Un modèle de matériau microfissuré pour les bétons et les roches." J. Méc. Th. Appl., 5 (3), 471-513 (in French).

Aveston, J., Cooper, G. A., and Kelly, A. (1971). "Single and Multiple Fracture." Proceedings National Physical Laboratory: Properties of Fiber Composites, IPC Science and Technology Press, Surrey, UK, 15-26.

Aveston, J., and Kelly, A. (1973). "Theory of Multiple Fracture of Fibrous Composites." J. Mater. Sci., 8, 352-362.

Bazant, Z. P. (1986). "Mechanics of Distributed Cracking." Appl. Mech. Rev., 39, 675-705.

Bazant, Z. P., and Pijaudier-Cabot, G. (1989). "Measurement of Characteristic Length of Nonlocal Continuum." ASCE J. Eng. Mat., 115 (4), 755-767.

Bentur, A., and Mindess, S. (1990). Fiber Reinforced Cementitious Composites. Elsevier, London, UK.

Boudon-Cussac, D. (1996). "De l'anisotropie des bétons renforcés de fibres courtes en acier.", $\mathrm{PhD}$ thesis, Université Paris 6, France (in French). 
Breysse, D., and Schmitt, N. (1991). "A Test for Delaying Localization in Tension. Numerical Interpretation through a Probabilistic Approach." Cem. Conc. Res., 21, 963-974.

Budiansky, B., Hutchinson, J. W., and Evans, A. G. (1986). "Matrix Fracture in Fiber-Reinforced Ceramics." J. Mech. Phys. Solids, 34 (2), 167-189.

Burr, A., Hild, F., and Leckie, F. A. (1995). "Micro-Mechanics and Continuum Damage Mechanics." Arch. Appl. Mech., 65 (7), 437456.

Burr, A., Hild, F., and Leckie, F. A. (1997). "Continuum Description of Damage in Ceramic-Matrix Composites." Eur. J. Mech. A/Solids, 16 (1), 53-78.

Chaboche, J.-L. (1982). "Le concept de contrainte effective appliquée à l'élasticité et à la viscoplasticité en présence d'un endommagement anisotrope." Colloque international du CNRS, 295, 31-43 (in French).

Cox, H. L. (1952). "The Elasticity and the Strength of Paper and other Fibrous Materials." Br. J. Appl. Phys., 3, 72-79.

Curtin, W. A. (1993). "Multiple Matrix Cracking in Brittle Matrix Composites." Acta Metall. Mater., 41 (5), 1369-1377.

Domergue, J.-M. (1995). "Relationships between the Macroscopic Behavior of Ceramic Matrix Composites and their Constituents Properties.", PhD thesis, University of California at Santa Barbara, CA, USA. 
Eshelby, J. D. (1957). "The Determination of the Elastic Field of an Ellipsoidal Inclusion and Related Problems." Proc. Roy. Soc. London, A 241, 376-396.

Germain, P., Nguyen, Q. S., and Suquet, P. (1983). "Continuum Thermodynamics." ASME J. Appl. Mech., 50, 1010-1020.

Guinea, G. V., Planas, J., and Elices, M. (1994). "Correlation Between the Softening and the Size Effect Curves." Proceedings Size Effect in Concrete Structures, E\&FN Spon Pubs., London, UK, 233-244.

Hild, F., Burr, A., and Leckie, F. A. (1996). "Matrix Cracking and Debonding in Ceramic-Matrix Composites." Int. J. Solids Struct., 33 (8), 1209-1220.

Hutchinson, J. W., and Jensen, H. M. (1990). "Models for Fiber Debonding and Fiber Pull-Out in Brittle Composites with Friction." Mech. Mater., 9, 139-163.

L'Hermite, S. (1960). "Volume Changes in Concrete." Proceedings 4th International Symposium on the Chemistry of Cement, 659-702. Lemaitre, J. (1992). A Course on Damage Mechanics. SpringerVerlag, Berlin, Germany.

Lemaitre, J., and Dufailly, J. (1977). "Modélisation et identification de l'endommagement plastique des métaux." Proceedings $3 e$ congrès français de mécanique, Grenoble, France.

Love, A. E. H. (1927). The Mathematical Theory of Elasticity. Cambridge University Press, Cambridge, UK.

Mazars, J., and Berthaud, Y. (1989). "Une technique expérimentale appliquée au béton pour créer un endommagement diffus et 
mettre en évidence son caractère unilatéral." C. R. Acad. Sci. Paris, Série II (t. 308), 579-584 (in French).

Mazars, J., Berthaud, Y., and Ramtani, S. (1990). "The Unilateral Behavior of Damaged Concrete." Eng. Fract. Mech., 35 (4/5), 629-635.

McMeeking, R. M., and Evans, A. G. (1990). "Matrix Fatigue Cracking in Fiber Composites." Mech. Mater., 9, 217-227.

Outwater, J. O., and Murphy, M. C. (1969). "On the Fracture Energy of Unidirectional Laminates." Proceedings 26th Annual Technical Conference of Reinforced Polymer/Composites Division of Plastic Industry, The Society of Plastics Industry, New-York, NY, USA, 1-8.

Rice, J. R. (1971). "Inelastic Constitutive Relations for Solids: An Internal Variable Theory and its Application to Metal Plasticity." J. Mech. Phys. Solids, 19, 433-455.

Sun, Z. (1989). "Une théorie tridimensionnelle des poutres élastiques hétérogènes et analyse non-linéaire des structures en béton armé.", $\mathrm{PhD}$ thesis, Université Paris 6, France (in French).

Volterra, V. (1907). "Sur l'équilibre des corps élastiques multiplement connexes." Annales Scientifiques de l'École Normale Supérieure, Paris, France, 24 (3), 401-518 (in French). 


\section{Appendix. Notations}
$\mathrm{A}, \mathrm{B}, \boldsymbol{\text { dimensionless constants }}$
d, D damage variables
$\mathcal{D} \quad$ intrinsic dissipation
$\mathrm{E}, \mathrm{E}_{\mathrm{f}}, \mathrm{E}_{\mathrm{m}} \quad$ elastic moduli of the fiber and matrix, respectively
$\mathrm{E}, \tilde{\mathrm{E}} \quad$ initial and current Young's modulus of the composite
f volume fraction of the fiber
$f_{s} \quad$ volume fractions of short fibers
$\mathrm{F}_{\mathrm{D}}, \mathrm{F}_{\mathrm{d}}, \mathrm{F}_{\mathrm{i}}$ functions
$G_{\mathrm{d}} \quad$ critical energy release rate
$\mathrm{G}_{\mathrm{m}} \quad$ shear modulus of the matrix
$\mathrm{H}, \mathrm{H}_{\mathrm{f}}, \mathrm{H}_{\mathrm{m}}$ heights
2L average distance between cracks
$l_{\mathrm{d}} \quad$ debond length at the fiber/matrix interface
$l_{\mathrm{f}} \quad$ slip length
$\mathrm{L}_{\mathrm{s}}, \sigma_{\mathrm{S}} \quad$ values of $\mathrm{L}$ and $\sigma$ at saturation
$\mathrm{T}_{\mathrm{d}}, \lambda_{\mathrm{d}}, \Sigma_{\mathrm{d}}$ dimensionless groups
$\mathrm{x}$ microscopic coordinate
$\mathrm{X} \quad$ back stress
$\mathrm{y}, \mathrm{Y}$ forces associated to the damage variables
$\mathrm{Y}_{\mathrm{c}} \quad$ critical energy release rate density
$\mathrm{Y}_{0} \quad$ normalizing energy release rate density
$\Delta \quad$ overall crack opening displacement
$\Delta^{\mathrm{e}}, \Delta^{\mathrm{i}} \quad$ elastic and inelastic contributions to $\Delta$
$\Delta \varphi \quad$ increase of the Gibbs' specific energy 


$\begin{array}{ll}\varepsilon & \text { strain } \\ \varepsilon^{\mathrm{a}}, \varepsilon^{\mathrm{a}-\mathrm{e}} & \text { additional strains } \\ \varepsilon^{\mathrm{e}} & \text { elastic strain } \\ \varepsilon^{\mathrm{i}} & \text { inelastic strain } \\ \varepsilon^{\mathrm{p}} & \text { permanent strain } \\ \varepsilon_{\mathrm{f}} \varepsilon_{\mathrm{m}} & \text { local strains in the fiber and matrix, respectively } \\ \psi & \text { Helmholtz free energy density } \\ \psi^{\mathrm{e}} & \text { recoverable part of the Helmholtz free energy density } \\ \psi^{\mathrm{i}} & \text { non-recoverable part of the Helmholtz free energy } \\ \psi_{\mathrm{f}}, \psi_{\mathrm{m}} & \text { density } \\ \omega, \Omega & \text { elastic energy densities in the fiber matrix, respectively } \\ \rho_{\mathrm{f}}, \rho_{\mathrm{f}}^{\mathrm{e}}, \rho_{\mathrm{f}}^{\mathrm{i}} & \text { additional stresses in the fiber } \\ \rho_{\mathrm{m}}, \rho_{\mathrm{m}}^{\mathrm{i}} & \text { additional stresses in the matrix } \\ \sigma & \text { applied stress } \\ \sigma_{\mathrm{d}} & \text { debond strength } \\ \sigma_{\mathrm{f}} & \text { stress in the fiber } \\ \sigma_{\mathrm{id}} & \text { debond stress } \\ \sigma_{\mathrm{mc}} & \text { matrix-cracking stress } \\ \sigma_{0} & \text { normalizing stress } \\ \tau & \text { shear strength } \\ & \end{array}$




\section{Figure Captions}

Figure 1: ID2 specimen configuration (after Mazars and Berthaud (1989)).

Figure 2: Choice of an elementary cell of length $2 \mathrm{~L}$ containing a matrix crack. A debond zone is characterized by a length $2 l_{\mathrm{d}}$

Figure 3: Stress / strain curve of an ID2 specimen with unreinforced concrete.

Figure 4: Measurements of the inelastic strain $\varepsilon^{\mathrm{i}}$, the damage parameter $\mathrm{D}$ by partial unloading.

Figure 5: Experimental and identified changes of the damage parameter $\mathrm{D}$ with the energy release rate density $\mathrm{Y}$ for 2 unreinforced concrete ID2 specimens.

Figure 6: Experimental and identified changes of the inelastic strain $\varepsilon^{i}$ with the applied stress $\sigma$ for 2 unreinforced concrete ID2 specimens.

Figure 7: Prediction of the damage variable $d$ versus applied stress $\sigma$ for unreinforced concrete ID2 specimens. 
Figure 8: Experimental and predicted changes of the permanent strain $\varepsilon^{p}$ with the maximum applied stress $\sigma$ for 2 unreinforced concrete ID2 specimens.

Figure 9: Comparison of changes of the inelastic strain $\varepsilon^{i}$ with the applied stress $\sigma$ for ID2 specimens with different volume fractions $\left(f_{s}=0 ., 0.1,0.3,0.6 \%\right)$ and fiber orientations $(0$, $\left.\pm 15, \pm 30^{\circ}\right)$

Figure 10: Comparison of changes of the damage parameter $\mathbf{D}$ with the energy release rate density $Y$ for ID2 specimens with different volume fractions $\left(f_{s}=0 ., 0.1,0.3,0.6 \%\right)$ and fiber orientations $\left(0, \pm 15, \pm 30^{\circ}\right)$. The symbols are experimental data and the solid line is the identification when $f_{s}=0$.

Figure 11: Comparison of stress / strain curves of ID2 specimens with different volume fractions $\left(f_{s}=0 ., 0.1,0.3,0.6 \%\right)$ and fiber orientations $\left(0, \pm 15, \pm 30^{\circ}\right)$. The symbols are experimental data and the solid line is the identification when $f_{s}=0$. 


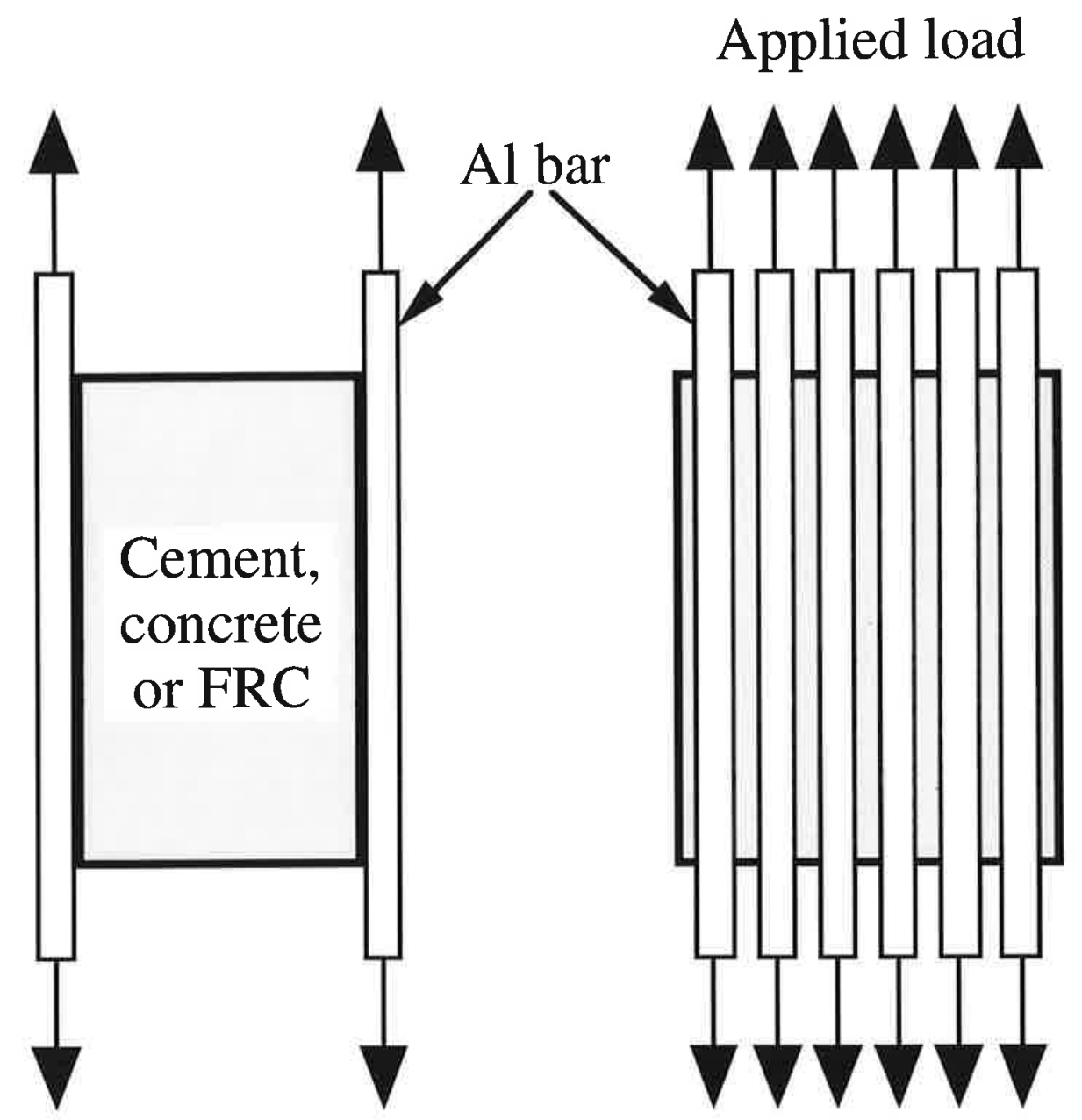

Figure 1 


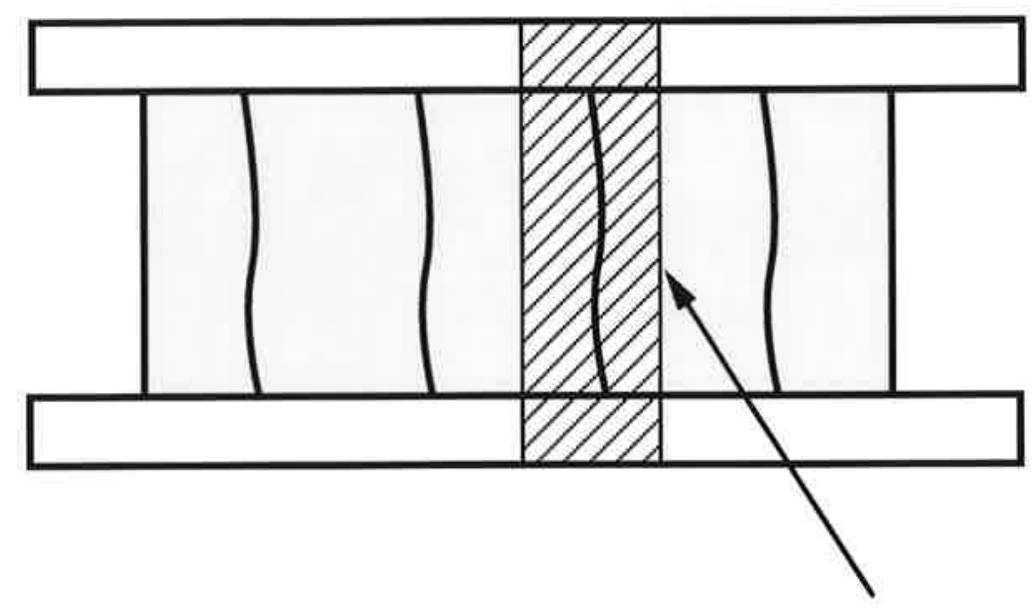

Elementary cell

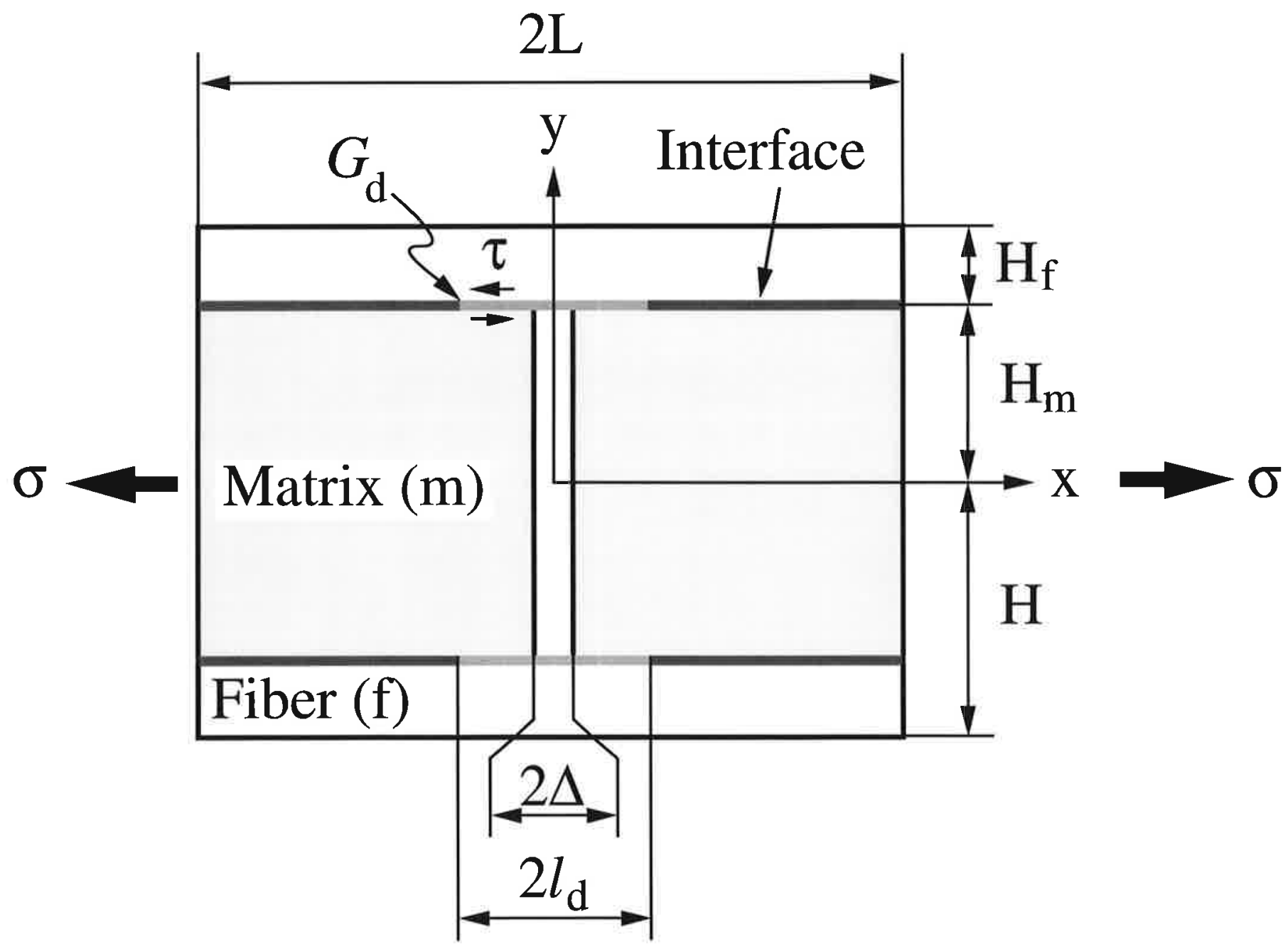

Figure 2 
Applied Stress, $\sigma(\mathrm{MPa})$

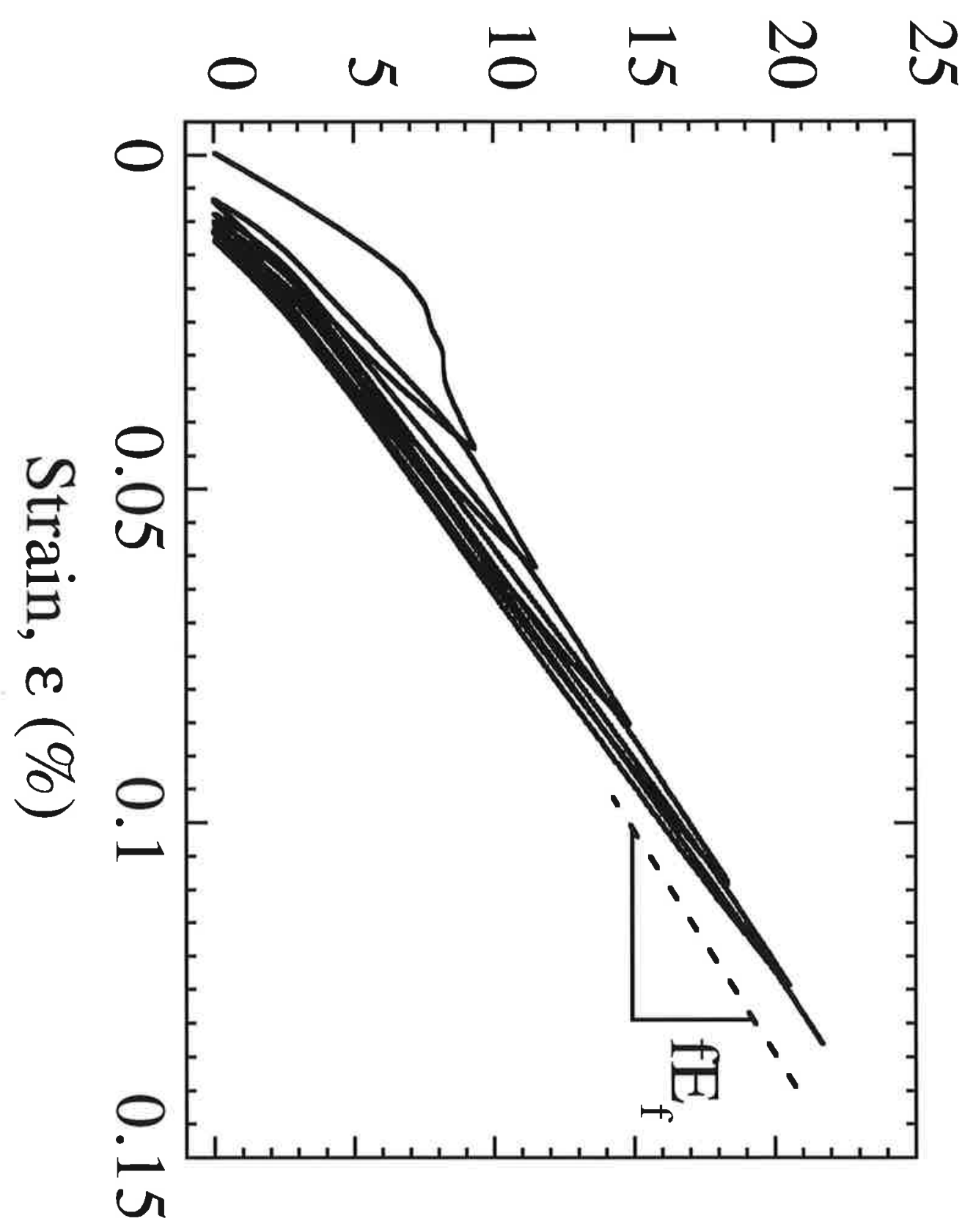

Figure 3 


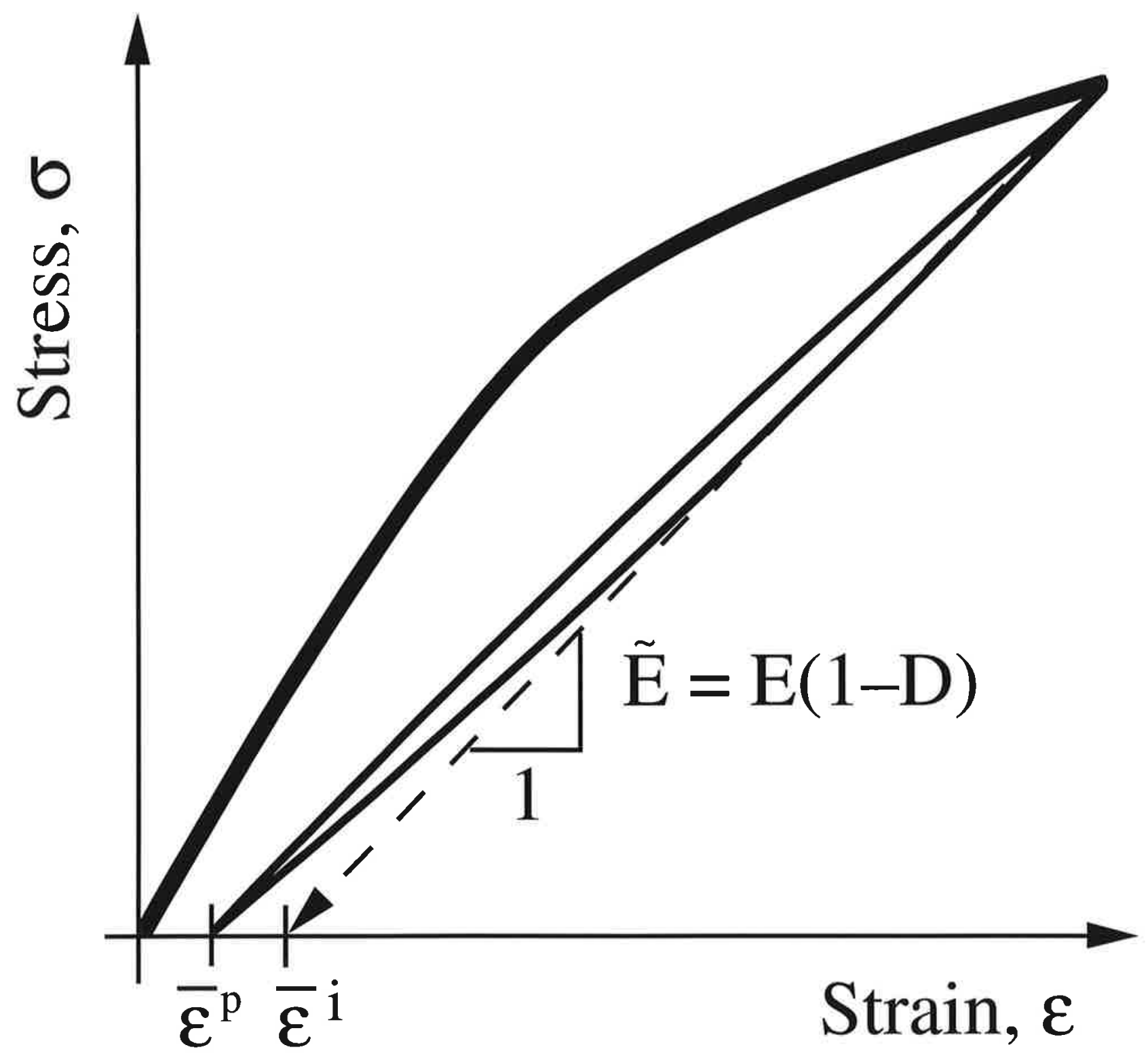

Figure 4 
Damage, D

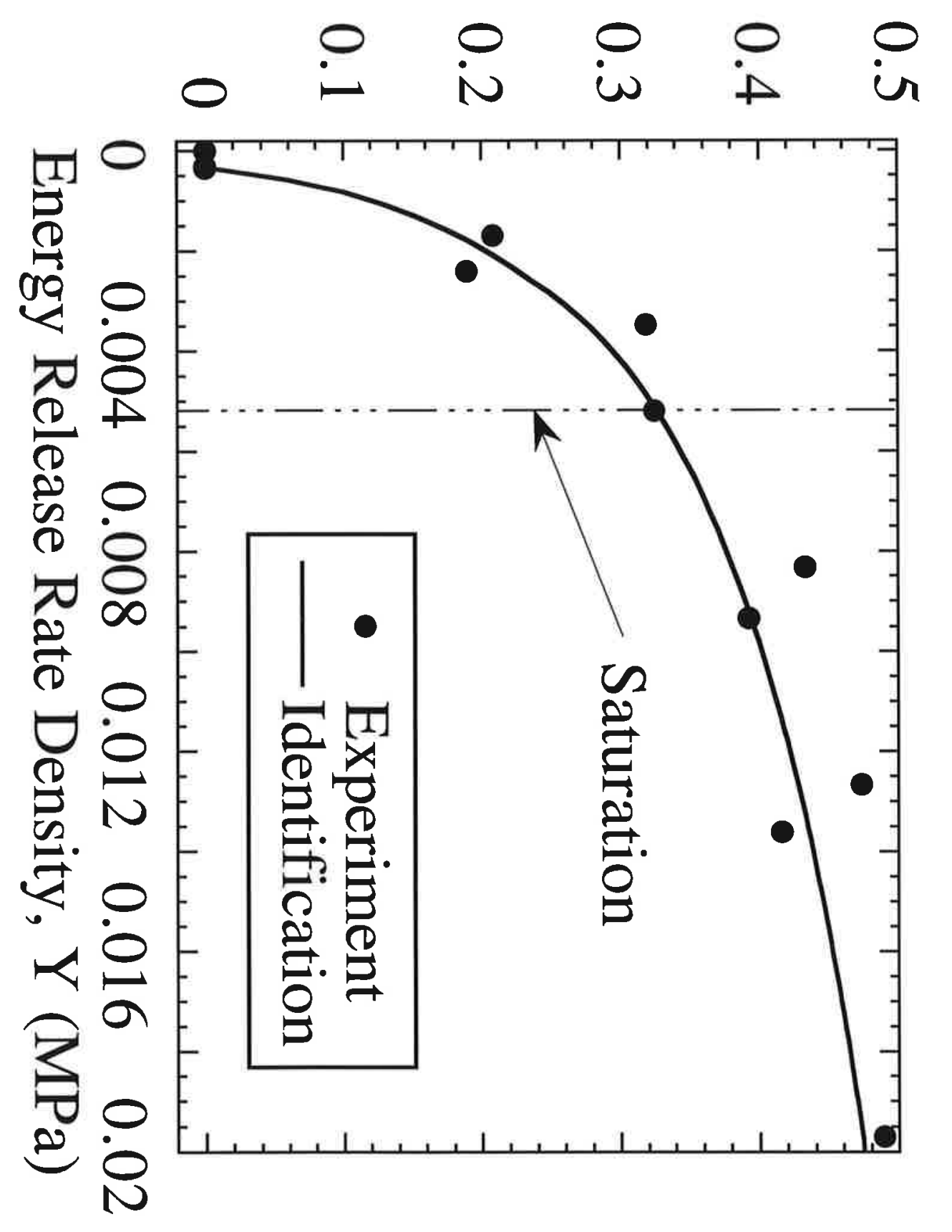

Figure 5 
Inelastic Strain, $\varepsilon^{\mathrm{i}}(\%)$

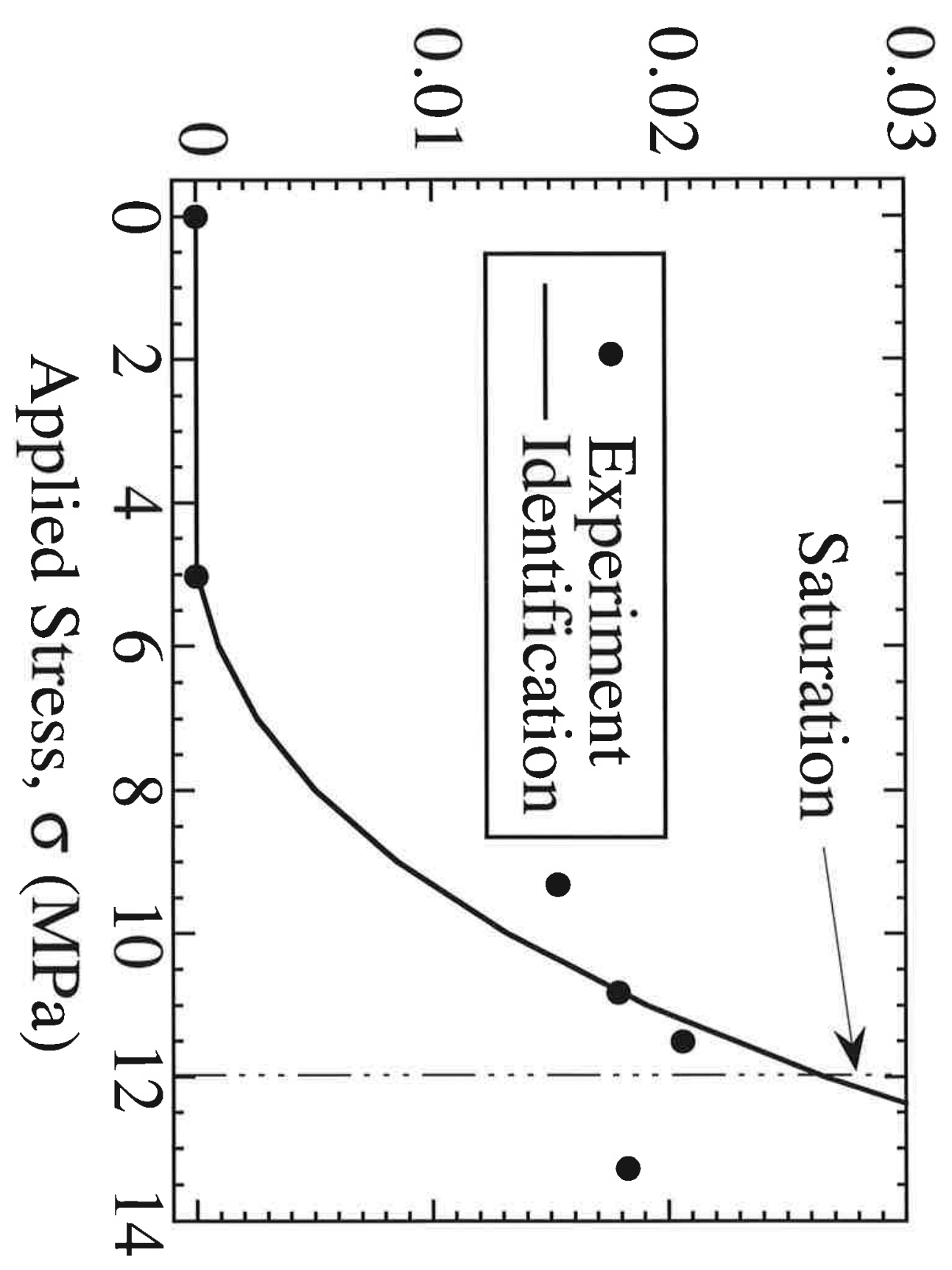

Figure 6 


\section{Normalized Damage Parameter, Ad}

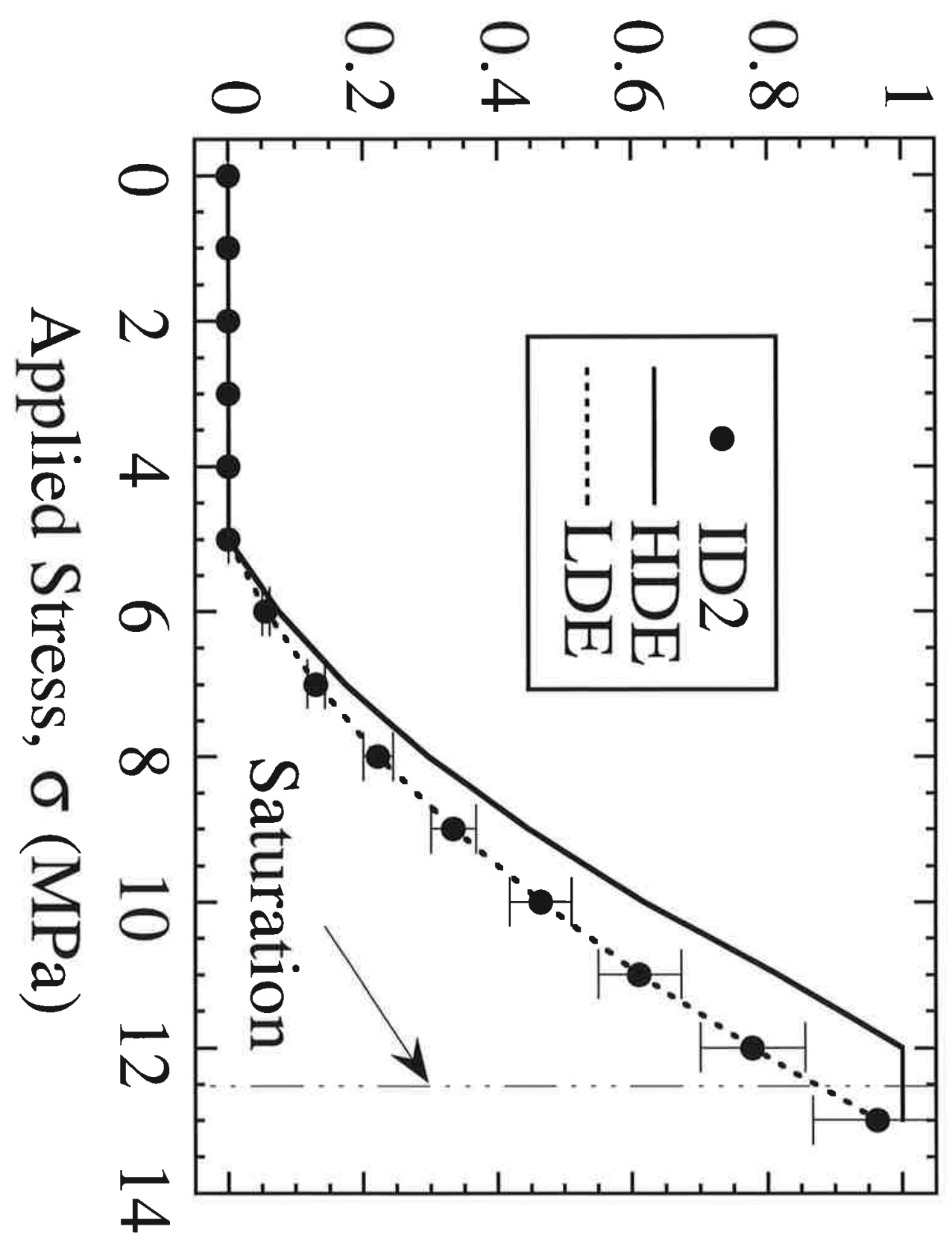

Figure 7 
Permanent Strain, $\varepsilon^{\mathrm{p}}(\%)$

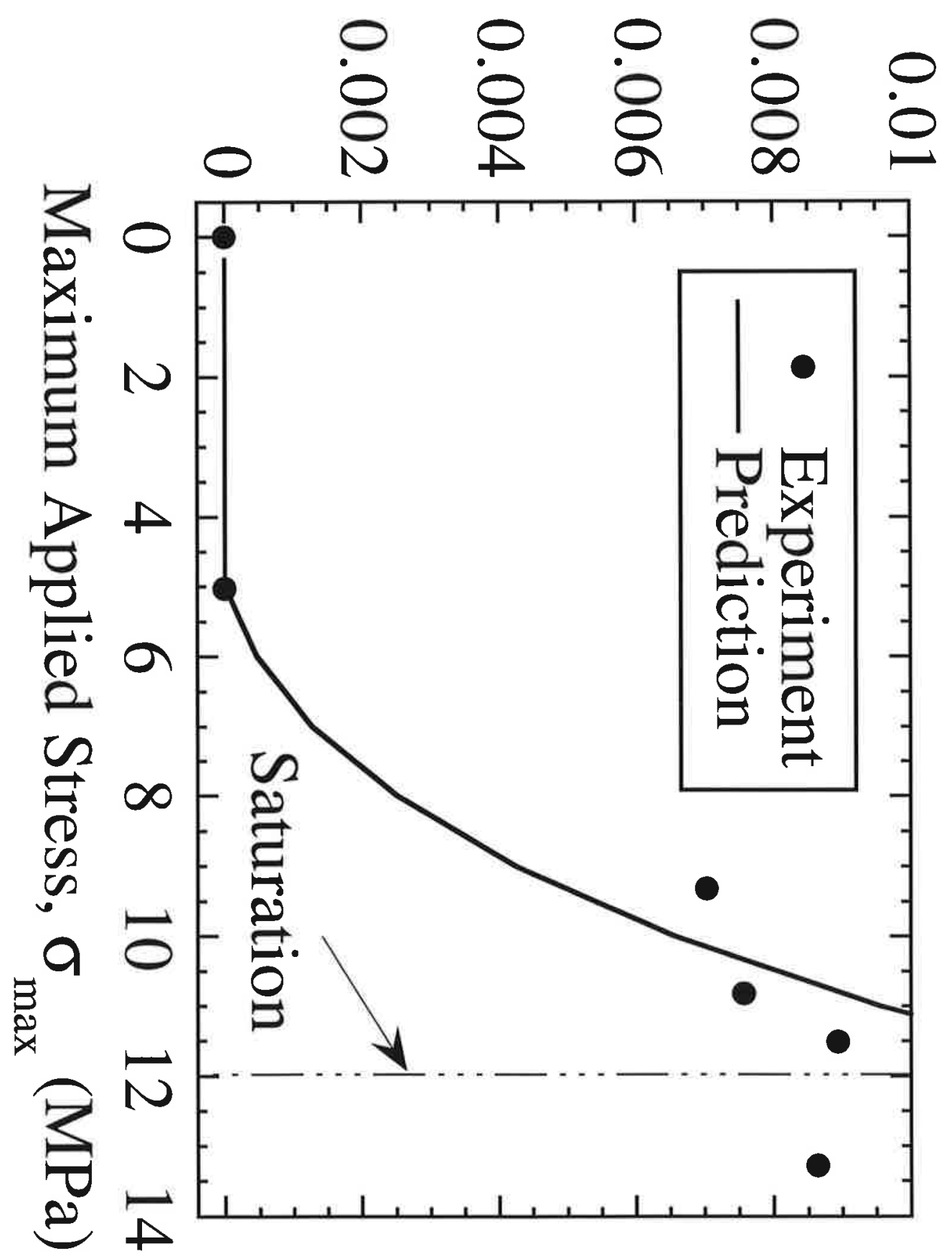

Figure 8 


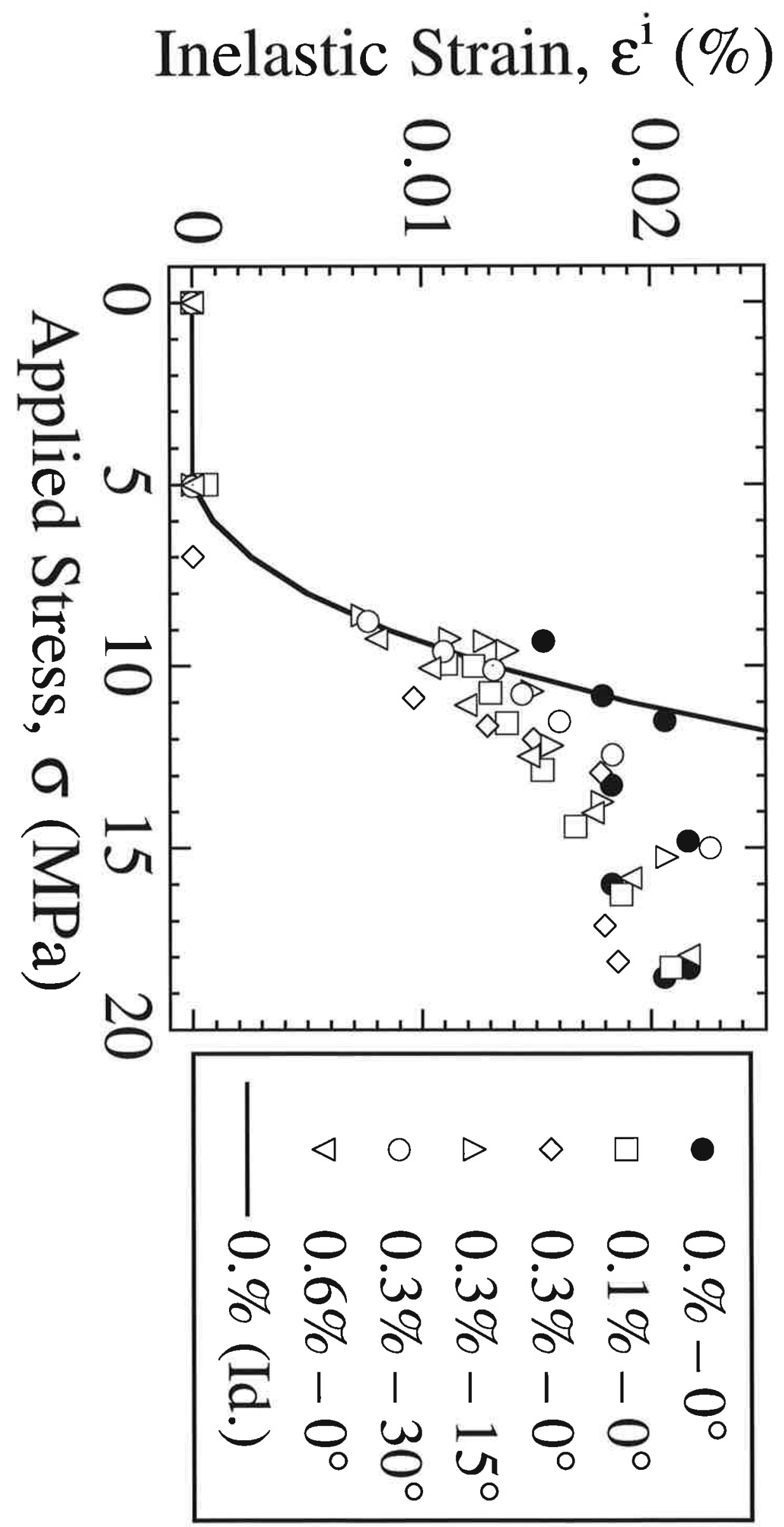

Figure 9 


\section{Damage, D}

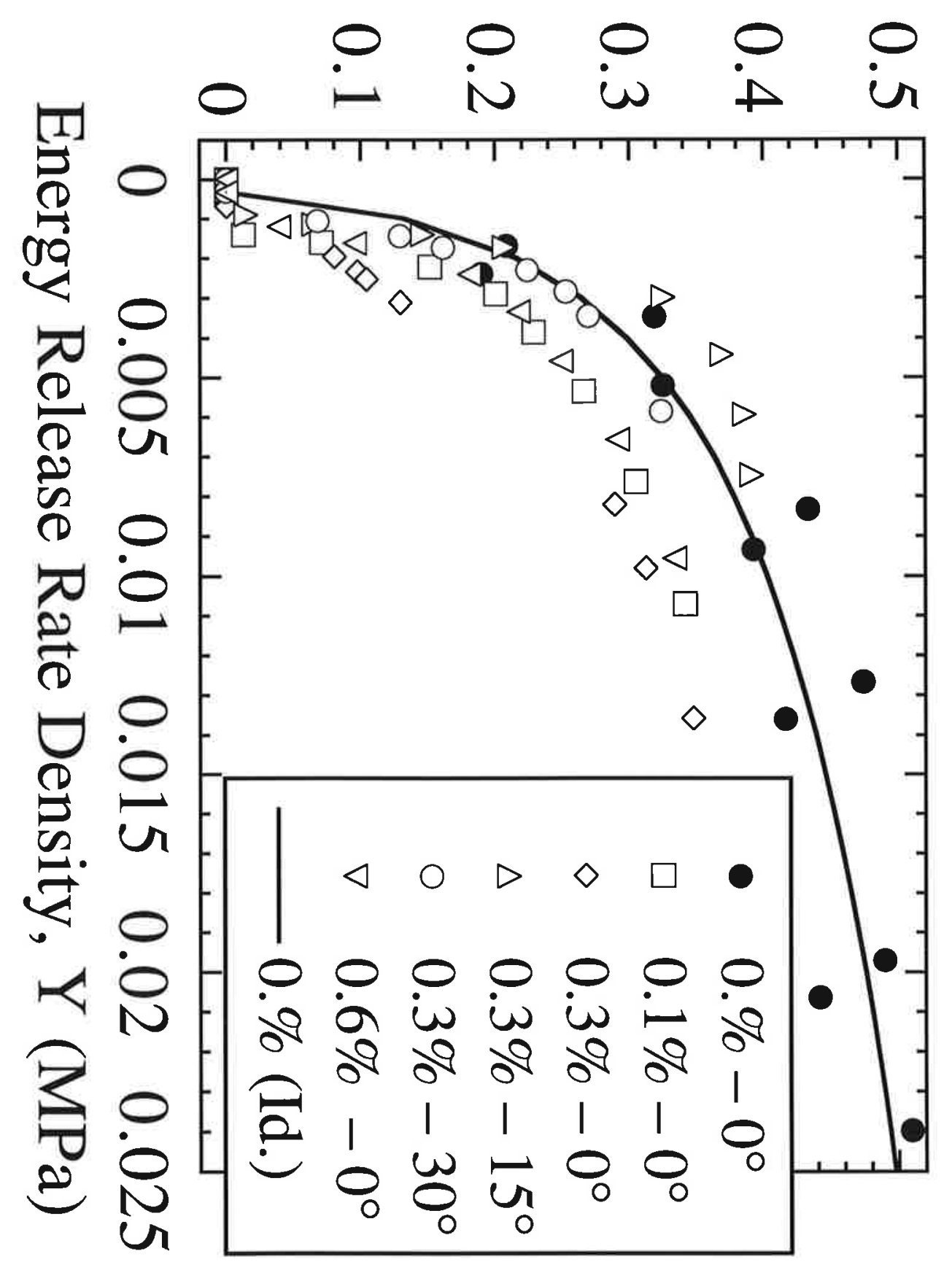

Figure 10 
Applied Stress, $\sigma(\mathrm{MPa})$

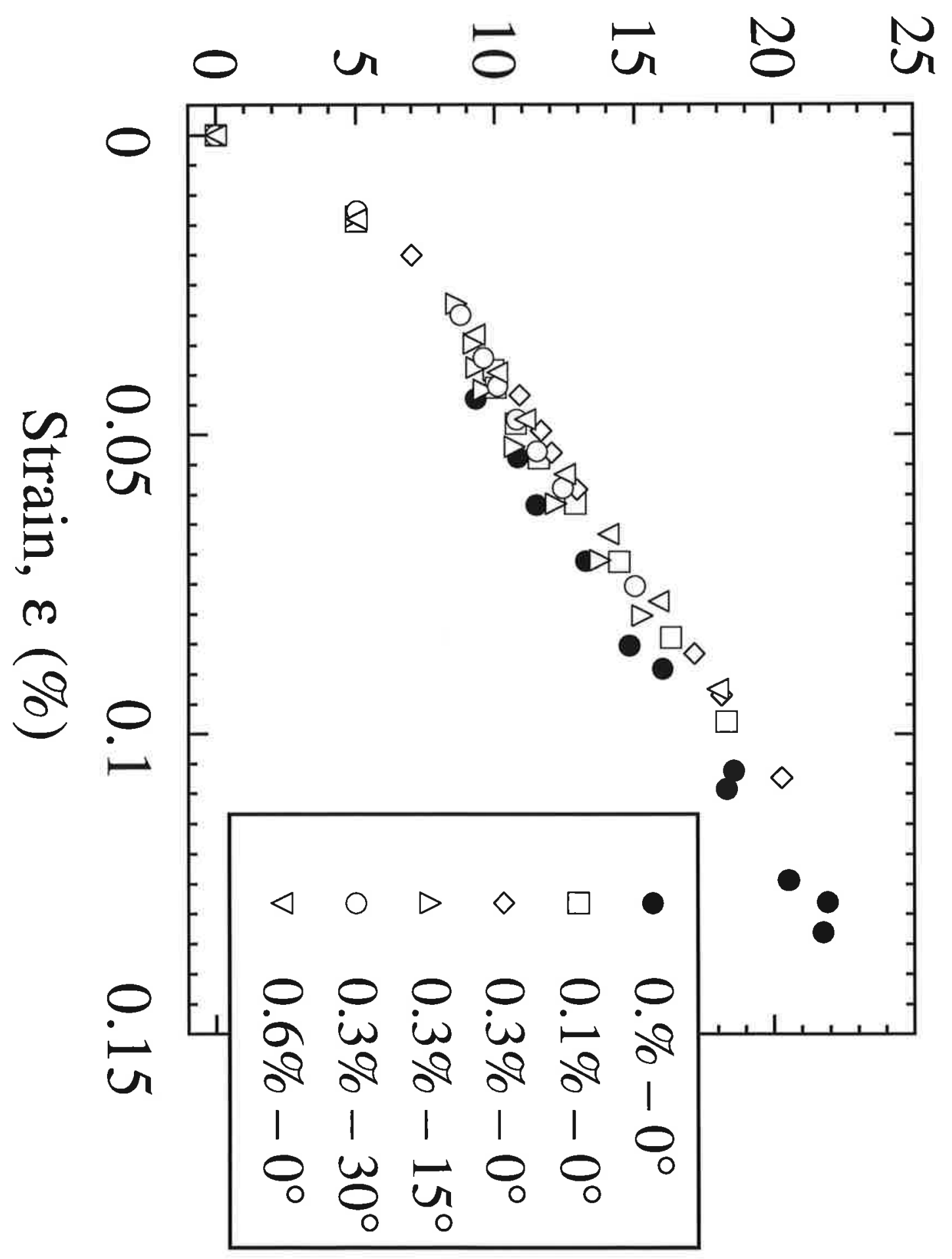

Figure 11 